\title{
Determinantes orçamentários, políticos e socioeconômicos da sucessão político-partidária: evidências sobre o comportamento eleitoral em municipios brasileiros
}

\author{
Tiago Carneiro da Rocha1 (D) , Juliana Maria de Araújo² (D), Antônio Carlos Brunozi Júnior ${ }^{3}$ \\ Universidade Federal de Viçosa, Viçosa-MG, Brasil.
}

\section{$凶$}

'tiago.c.rocha@ufv.br 2juliana.m.araujo@ufv.br 3acbrunozi@yahoo.com.br

Editado por:

Orleans Silva Martins

Paulo Roberto da Cunha

\section{Resumo}

Objetivo: Papesar das ações para a intensificação da governança, da transparência e da accountability, existem ainda tendências de os governantes manipularem resultados fiscais, orçamentários e/ou utilizarem informações políticas e socioeconômicas para direcionarem suas ações em benefício próprio, principalmente visando as suas reconduções ao cargo ou de seus partidos. Com isso, o objetivo desta pesquisa foi avaliar a interveniência de aspectos orçamentários, políticos e socioeconômicos na reeleição de gestores e na recondução de partidos nos municípios brasileiros.

Método: coletaram-se dados dos municípios brasileiros com população acima de 100 mil habitantes para os ciclos eleitorais de 2004, 2008, 2012 e 2016. Os dados foram submetidos a Regressão Logística com dados em painel.

Resultados: a probabilidade de reeleição do gestor municipal ou a recondução do seu partido ao cargo é influenciada por fatores relacionados aos eleitores que premiam aqueles prefeitos que realizam mais investimentos municipalmente, melhorando a qualidade de vida populacional, que possibilitam a minimização das desigualdades através da transferência direta de renda e que tenham maiores chances de estabelecimento de cooperação entre as demais esferas de governo por meio do alinhamento partidário. Contribuição: a contribuição teórica é de que a assimetria informacional, as escolhas públicas que envolvem a influência de elementos humanos e institucionais, e a percepção pelo eleitor da justiça social, são fatores em conjunto que explicam a sucessão políticopartidária. Como contribuição prática, discorre-se que administradores públicos podem se utilizar do aparato estatal para benefícios próprios - levando a influenciar o voto do eleitor - que não exerce a participação social e/ou não se utiliza das informações públicas e disponíveis para o conhecimento adequado da gestão e governança municipal.

Palavras-chave: Reeleição de prefeitos. Recondução de partidos políticos. Determinantes eleitorais.

Como citar:

Rocha, T. C. da, Araújo, J. M. de, \& Brunozi Júnior, A. C. . (2021). DETERMINANTES ORÇAMENTÁRIOS, POLIITICOS E SOCIOECONÔMICOS DA SUCESSẤO POLÍTICO-PARTIDÁRIA: EVIDÊNCIAS SOBRE O COMPORTAMENTO ELEITORAL EM MUNICÍPIOS BRASILEIROS. Advances in Scientific and Applied Accounting, 14(3). Recuperado de https://asaa.anpcont.org.br/index.php/asaa/article/view/803 


\section{Introdução}

A o final dos anos 80 e início dos 90, ocorreram diversas mudanças culturais nas entidades do setor público. Em uma delas, a ineficiência do Estado, o excesso de burocracia, a prestação de contas ineficiente, somados à sua incapacidade de prover bens e serviços à população, ensejaram uma nova reforma na Administração Pública (Islam, 2015; Kalimullah et al., 2012). Essa reforma, denominada New Public Management (NPM), inovou com a recomendação de uma administração que considerasse os cidadãos como clientes, melhorando a prestação de serviços públicos e a promoção do bem-estar social (Islam, 2015).

Sob o paradigma da NPM, há uma tendência de incorporação pelo setor público de práticas de gestão do setor privado, refletindo na reformulação e no aprimoramento dos relatórios financeiros e das informações contábeis divulgadas. Além disso, as abordagens do setor privado envolvem "em especial a descentralização, foco em resultados e a medição do desempenho financeiro. A NPM também está relacionada aos conceitos de desempenho, economia, eficiência e eficácia" (Cunha, et al., 2018, p. 407, tradução nossa).

As entidades públicas, de modo geral, possuem como objetivo principal a prestação de serviços à sociedade, diferentemente do setor privado que visa a obtenção de lucros e o retorno financeiro aos seus investidores (Conselho Federal de Contabilidade [CFC], 2016). Neste sentido, as modificações provocadas pela NPM na contabilidade do setor público aumentaram a demanda por qualidade das informações para o processo de tomada de decisões, mais transparência e responsabilização (accountability) na gestão pública (Cunha et al., 2018). Ademais, as informações contábeis se tornaram importantes fontes de conteúdo acerca da forma como os serviços públicos são prestados e sobre os recursos disponíveis, auxiliando contribuintes, doadores e outras entidades na tomada de decisão (CFC, 2016). Desse modo, espera-se que as informações contábeis permitam que os eleitores tenham uma melhor noção sobre como os recursos públicos estão sendo aplicados pelos gestores públicos, sendo cruciais nos processos de eleição e reeleição dos mesmos.

Sobre isso, há de se mencionar que, no Brasil, a reeleição é prevista pela Emenda Constitucional (EC) n 16/1997, que alterou o $\S 5^{\circ}$ do art. 14 da Constituição Federal (CF) de 1988, publicando a seguinte redação: "O Presidente da República, os Governadores de Estado e do Distrito Federal, os Prefeitos e quem os houver sucedido, ou substituído no curso dos mandatos poderão ser reeleitos para um único período subsequente" (Brasil, 1997).

Apesar de todos os avanços propiciados pela NPM, principalmente nos quesitos de transparência e accountability, na literatura se discutiu sobre as possibilidades de os governantes manipularem resultados e/ou informações e de direcionarem suas ações para atingir benefício próprio e/ou de outros atores institucionais dotados de influências ou lobbies. Dentre elas, destaca-se a utilização do comportamento oportunista por parte dos governantes com o propósito de se reeleger, conforme as discussões de Balaguer-Coll, Brun-Martos (2013); Liendo (2014) e Cavalcante (2016). Os referidos autores discorreram que os governantes utilizam de estratégias e de manipulações oportunistas que possam acarretar em sua recondução ao cargo, podendo utilizar de diversos métodos para tal.

A manipulação realizada pelo gestor teria como objetivo o aumento da popularidade do governante perante seus eleitores ou grupos de apoio, seguindo políticas favoráveis e que representassem os interesses deles (Alesina \& Roubini, 1992; Alesina, 1988). Pouco tempo antes da ocorrência das eleições, os políticos, aproveitando-se da assimetria de informação existente, tenderiam a manipular as condições fiscais e econômicas para aumentar sua probabilidade de reeleição, comportando-se de forma mais oportunista na medida em que sua margem para vitória é menor (Rogoff \& Sibert, 1988; Aidt, Veiga, \& Veiga, 2011; Akhmedov \& Zhuravskaya, 2004). Como exemplo, tem-se a constatação de Sakurai e Menezes-Filho (2011), de que nos anos eleitorais havia um acréscimo significativo nos gastos de mais de 2.500 municípios brasileiros no período de 1989 a 2005, sugerindo a ocorrência de ciclos oportunistas nestes locais.

Já os eleitores, preocupados com seu bem-estar, avaliariam de forma indireta a competência do gestor, recompensando-o por meio da reeleição ou recondução do seu partido (Nordhaus, 1975; Drazen \& Eslava, 2010). Não obstante, certas ações poderiam ser compreendidas pelos eleitores como sendo de cunho oportunista, ocasionando na penalização do gestor (Brender \& Drazen, 2008). Para isso, o eleitor poderia comparar - comportamento do gestor com que é usualmente realizado, avaliando as ações realizadas com base no comportamento passado e construindo uma base avaliativa para a tomada de decisão acerca de seu voto (Nordhaus, 1975). 
Meneguin et al. (2005) apresentaram a tentativa de perpetuação dos governantes no cargo a partir de manipulações nas políticas monetária e fiscal, além de constatarem a existência de um ciclo, em que os governantes, ao perceberem a influência da economia no voto, utilizam de política monetária para aumentar o emprego e, assim, melhorar a economia. No entanto, existem obstáculos que impedem a plena utilização destes mecanismos pelos governantes, como a limitação de número de mandatos; as legislações que restringem as ações governamentais no ano eleitoral e a forma de realização de despesas, e as consequências das informações auferidas por pesquisas de opinião no período pré-eleitoral (Meneguin et al., 2005).

Outrossim, diversos estudos buscaram identificar os aspectos determinantes na reeleição de gestores públicos, constatando-se a influência de variados fatores de cunho orçamentário, institucional, político e socioeconômico. Dentre os aspectos orçamentários, destacam-se o gasto público encontrado nos estudos de Brender (2003), Balaguer-Coll e Brun-Martos (2013), Silva e Braga (2013), Balaguer-Coll et al. (2014), Chortareas et al. (2016) e Cavalcante (2016). Também foram identificadas pesquisas que têm por objeto a análise das receitas auferidas, a exemplo de Meneguin e Bugarin (2001), Sakurai e Menezes-Filho (2007), Silva e Braga (2013), BalaguerColl et al. (2014) e Dias et al. (2018); bem como das transferências governamentais, como encontrado em Balaguer-Coll e Brun-Martos (2013), Balaguer-Coll et al., (2014) e Chortareas et al. (2016).

Já os aspectos políticos são representados pelas variáveis de ideologia, a exemplo dos trabalhos de Balaguer-Coll e Brun-Martos (2013) e Balaguer-Coll et al. (2014); além do alinhamento partidário, conforme Sakurai e MenezesFilho (2007), Silva e Braga (2013) e Cavalcante (2016). Os aspectos socioeconômicos foram caracterizados pela taxa de desemprego, encontrada em Balaguer-Coll e Brun-Martos (2013) e Balaguer-Coll et al. (2014); e pelo Produto Interno Bruto (PIB), conforme Silva e Braga (2013); pela taxa de mortalidade infantil e taxa de analfabetismo, encontrados em Shikida et al. (2009) e pelo Índice de Desenvolvimento Humano (IDH), tal como em Dias et al. (2018). Por fim, retrataram-se ainda aspectos institucionais, representados pela intervenção federal e nível de competitividade eleitoral, a exemplo de Liendo (2014).

Com isso, percebe-se a importância da compreensão acerca dos determinantes que podem interferir na reeleição de um gestor público ou na recondução do seu partido, motivando o comportamento oportunista por parte dos mesmos a fim de permanecer no cargo. Para Aidt et al. (2011), os motivos ou fatores intervenientes econômicos, fiscais e políticos são os principais para os políticos sistematicamente manipularem as condições de um local e aumentarem suas chances de reeleição. Segundo Cunha et al. (2018), num ambiente público dotado de conflitos entre o agente (prefeitos) e o principal (eleitores), os prefeitos buscam agir em interesse próprio, maximizando seu benefício pessoal e ocasionando problemas de agência, incorrendo em custos para os eleitores.

Esse comportamento oportunista também é abordado pela Teoria da Escolha Pública, que compreende as escolhas feitas como o resultado das preferências dos agentes em uma sociedade composta por indivíduos egoístas (ou preferencialistas), que podem preferir seu benefício próprio em detrimento do coletivo (Pereira, 1997), mas nesta teoria a "escolha pública" é influenciada por todo - processo político, envolvendo as eleições, eleitores, legislação, tomadas de decisão etc. No entanto, ainda se pode mencionar que o eleitor pode perceber as ações do gestor na ótica da Teoria da Justiça, de que os recursos e as transferências de rendas são ações consideradas como justas e necessárias para os votantes.

Assim, esta pesquisa tem a seguinte indagação: Em que medida fatores orçamentários, políticos e socioeconômicos são determinantes para a reeleição de prefeitos ou recondução do seu partido nos municípios brasileiros? Objetivamente, avaliou-se a interveniência de aspectos orçamentários, políticos e socioeconômicos na reeleição de gestores e na recondução de partidos nos municípios brasileiros.

Diferentemente dos estudos pré-existentes, cuja maioria se concentra em investigar estados ou um grupo de municípios específicos (Barreto, 2009; Cervi, 2002; Dias et al., 2018; Silva \& Braga, 2013; Veiga, Santos, \& Neves, 2011), esta pesquisa, baseada no pressuposto da assimetria informacional da Teoria de Agência, bem como nas Teorias da Escolha Pública e da Justiça, identificou os determinantes capazes de interferir na reeleição de prefeitos ou recondução de partidos em municípios brasileiros, compreendendo, de modo amplo, aqueles que possuam mais de 100 mil habitantes.

A escolha dos municípios com população acima de 100 mil habitantes, deu-se, inicialmente, por estes representarem aproximadamente $56 \%$ da população brasileira e pela maior disponibilidade de informação de municípios que possuem um porte maior, devido à 
capacidade institucional em gerá-las. Nesta pesquisa, considerou-se um país Code-Law, em desenvolvimento, com sistema político peculiar e dimensão territorial ampla, diferentemente das investigações de Aidt et al. (2011), em Portugal, Drazen e Eslava (2010), na Colômbia, Akhmedov e Zhuravskaya (2004), na Rússia, e Brender e Drazer (2008) em nações desenvolvidas.

Como diferencial deste estudo, foi considerado um período temporal mais amplo (quatro ciclos eleitorais), possibilitando evidenciar a recondução de partidos ao cargo de chefe do executivo municipal mesmo diante da impossibilidade de novas reeleições, demonstrando a perpetuação de partidos políticos no poder. Pesquisas anteriores foram restritas a dois, três ciclos eleitorais, a exemplo de Mendes e Rocha (2004b), Pereira e Renno (2007) e Cavalcante (2015). Além disso, este estudo inova ao considerar uma variedade de indicadores orçamentários, políticos e socioeconômicos, incluindo também os efeitos das informações contábeis. Quando se ressalva a inserção da Contabilidade, a mesma se deu com dados considerando o regime de competência, fato trazido pela adoção das International Public Standards Accounting Sector (IPSAS) no país, que substituiu o regime de caixa. Destaca-se que as informações referentes ao Programa Bolsa Família até então não tinham sido utilizadas em modelos de previsão de eleições municipais, sendo prudente adotálas tendo em vista a gestão compartilhada deste programa social.

Como contribuição, este estudo apontou quais dimensões poderiam ser alvo de um comportamento oportunista por parte do gestor público, tendo em vista que as mesmas poderiam exercer influência sobre a popularidade do gestor e, consequentemente, na probabilidade de sua reeleição ou da recondução do seu partido ao cargo. Evidenciou-se a possibilidade de um comportamento situacionista sobre os alinhamentos político-partidários com governadores e presidente, além de usufruir da gestão compartilhada do programa Bolsa Família e da aplicação de recursos públicos em gastos de capital para promoção da reeleição ou recondução.

A relevância está na importância da eleição, reeleição ou recondução para a definição de prefeitos, responsáveis pela gestão das entidades públicas locais, e consequentemente, pela consecução ou não de seus objetivos, sendo esses oferecer serviços públicos à sociedade. Apesar de o fenômeno da reeleição não ser mais tão ałual, ainda é incipiente a compreensão dos aspectos que podem influenciar na probabilidade de reeleição dos gestores ou na recondução do partido, principalmente pela motivação que o gestor pode ter para um comportamento oportunista visando tais objetivos.

\section{Referencial Teórico}

\subsection{Fatores determinantes da reeleição de gestores públicos}

Em uma democracia, é extremamente importante a responsabilização, permitindo assegurar aos cidadãos que os agentes públicos possam responder por seus atos (Mulgan, 2003). Desse modo, a prestação de contas se torna essencial para o estabelecimento de diálogo e deliberações entre os governantes e os cidadãos. Além do que, Bovens et al. (2008) argumentam que a responsabilização é apresentada em termos de um modelo de agente-principal, uma vez que os cidadãos transferem sua soberania para os seus representantes populares. Jensen e Meckling (1976) afirmam que a relação de agência pode ser compreendida como um contrato entre uma ou mais pessoas (denominados principais), que empregam outra pessoa (denominada agente) para executar algo em seu nome, dando-lhe o poder de decisão.

Uma vez que a administração local é caracterizada pela existência de conflitos de interesse de cunho oportunista, a Teoria de Agência é relevante para o entendimento das relações entre o principal e o agente no âmbito público, possibilitando a compreensão sobre a transferência da soberania dos cidadãos aos seus representantes políticos nos processos eleitorais. Além do que, a existência de assimetria de informação entre o principal e o agente é motivadora de um comportamento do gestor visando o seu próprio interesse, principalmente no que tange à reeleição (Cavalcante, 2016).

Esse comportamento é justificado pelo fato de que o gestor público possui melhores informações sobre sua própria competência, enquanto os eleitores não dispõem de meios diretos para mensurá-la e se utilizam de outros métodos para avaliar a gestão, como é o caso da análise dos gastos realizados (Drazen \& Eslava, 2010).

No período próximo às eleições os gestores, tirando vantagem da assimetria informacional, tentariam parecer - mais competentes possível perante seus eleitores, mas a racionalidade destes últimos poderia limitar esse oportunismo (Alesina \& Roubini, 1992). Certos eventos como, por exemplo, um elevado crescimento econômico próximo ao período eleitoral, poderia desencadear um sentimento de desconfiança por parte do eleitorado, 
afetando os gestores de forma negativa (Brender \& Drazen, 2008). Assim, há a constatação de que há, de fato, uma resposta por parte dos eleitores, ora recompensando os governantes através do voto, ora os punindo (BalaguerColl \& Brun-Martos, 2013). E, para tanto, assume-se que a reeleição pode ser influenciada por diversos fatores.

A busca pelo interesse próprio dos governantes em detrimento do bem-estar social é destacada também na Teoria da Escolha Pública, que discute sobre a influência de diversos agentes sobre a decisão dos governantes e sobre a implementação das políticas públicas (Pereira, 1997; Santos et al., 2021). Nessa perspectiva, a escolha coletiva seria fruto das preferências de agentes dotados de interesses pessoais que motivam sua conduta (Pereira, 1997). Incluem-se também fatores não humanos, como a legislação, a eleição e a estrutura governamental.

A Teoria da Escolha Pública pode ser aplicada na análise dos gastos governamentais, sendo que uma das mais relevantes decisões tomadas é a respeito de como serão realizadas as despesas (Santos et al., 2021). Como forma de minimizar o comportamento oportunista nestas situações, foram instituídos mecanismos de controle e responsabilização para a gestão pública, como a Lei de Responsabilidade Fiscal que, dentre outros aspectos, fixa limites (aqui está a legislação como limitadora e influente na escolha pública) para as despesas com pessoal (Medeiros et al., 2017). No entanto, ainda há potencial para aumento de gastos de forma oportunista em áreas de gestão mais complexa e com maior presença de assimetria informacional, como é o caso da saúde, educação e assistência social (Santos et al., 2021).

Ainda no que se refere à busca do bem-estar geral, que pode ter relação com a sucessão político-partidária, temse a Teoria da Justiça, segundo a qual os princípios da justiça seriam a base do acordo entre cidadãos livres e racionais que buscam seu próprio interesse (Rawls, 1971). Programas sociais, a exemplo do Bolsa Família, que tenham como propósito a melhoria das condições de vida da população menos favorecida, seriam então aceitos por propiciar uma sociedade mais bem ordenada e pautada na justiça social (Calgaro, 2016).

A Teoria da Justiça poderia ser aplicada também ao orçamento público, compreendendo as transferências financeiras governamentais de renda como uma ação que visa à justiça distributiva, tornando-se um instrumento de repartição da riqueza nacional e equalizadora dos desequilíbrios econômicos existentes (Portella \& Teixeira, 2016), favorecendo políticos à sua reeleição que se "esforçam" para manter esses benefícios.

\subsubsection{Aspectos orçamentários}

Em relação aos aspectos orçamentários, verificouse que as despesas, tanto totais quanto correntes e de capital, podem exercer influência sobre a reeleição dos gestores. A literatura evidencia que os governantes tendem a majorar os gastos públicos antes das eleições, principalmente os relacionados aos investimentos, numa tentativa de se reeleger ou reconduzir seu partido (Drazen \& Eslava, 2010). Como exemplo, ao analisarem dados de 85 países pelo período de 21 anos, Shi e Svensson (2006) constataram que o déficit fiscal governamental aumentava, em média, em 1\% do Produto Interno Bruno nas eleições. Esse aumento nas despesas ocasionaria uma maior diferença de votos entre o governante e seus oponentes, sugerindo que o comportamento oportunista pode ser favorável ao gestor (Aidt et al., 2011).

Em relação à despesa total, alguns autores verificaram que o incremento nos gastos pode majorar a probabilidade de reeleição (Balaguer-Coll et al., 2014; Balaguer-Coll \& Brun-Martos, 2013; Chortareas et al., 2016). Por outro lado, Silva e Braga (2013) concluíram que governantes que aumentam suas despesas em anos de eleição reduzem a probabilidade de se reeleger. De modo específico, com relação às despesas correntes, os autores Brender (2003) e Balaguer-Coll et al. (2014) encontraram resultados semelhantes aos de Silva e Braga (2013), indicando que há uma punição por parte do eleitor aos gestores que potencializam seus gastos no último ano de mandato.

No entanto, de modo complementar, com relação às despesas de capital, Balaguer-Coll e Brun-Martos (2013) e Balaguer-Coll et al. (2014) constataram uma relação positiva com a probabilidade de reeleição, de forma que os eleitores tendem a avaliar positivamente os políticos que realizam dispêndios que possuem mais visibilidade perante os eleitores (Balaguer-Coll et al., 2014). Tal resultado também foi encontrado no estudo de Cavalcante (2016) ao analisar a representatividade dos dispêndios de capital sobre as receitas totais dos municípios, concluindo que os esforços na construção de obras - escolas, hospitais, pavimentação e saneamento - são recompensadas pelos eleitores. Logo, antes das eleições os gestores teriam incentivos para aumentar a oferta de bens públicos, na esperança de que esta seja compreendida pelos eleitores como um sinal de sua competência (Shi \& Svensson, 2006).

Já sobre o nível de endividamento dos entes federativos, 
Balaguer-Coll et al. (2014) e Meneguin e Bugarin (2001) apresentaram em seus resultados uma preocupação dos governantes na contratação de empréstimos, já que existe uma tendência de cautela nos primeiros mandatos dos gestores públicos. Isso se dá pela capacidade de as dívidas contratadas terem impactos futuros, causando um comprometimento das receitas públicas, em que, quanto maiores as chances de reeleição, maior será o cuidado com o endividamento (Meneguin \& Bugarin, 2001).

No âmbito das receitas, destaca-se a influência das receitas totais, tributárias e de transferências. Em relação à receita total, Meneguim e Bugarin (2001) e Silva e Braga (2013) verificaram uma relação positiva em relação à probabilidade de reeleição. Já no tocante às receitas tributárias, os resultados são divergentes. Uma parcela dos autores verificou que as receitas tributárias influenciam positivamente nas chances de reeleição dos gestores (Balaguer-Coll et al., 2014; Sakurai \& Menezes-Filho, 2008; Sakurai \& Menezes-Filho, 2007). Essa relação denotaria uma preferência dos eleitores pelo aumento na disponibilidade dos recursos para possíveis gastos futuros do governo, apesar de isso resultar em uma maior arrecadação de impostos dos cidadãos (Balaguer-Coll et al., 2014). Além do que, "as receitas da tributação local também são uma proxy para o desempenho econômico do município" (Sakurai \& Menezes-Filho, 2008, p. 305, tradução nossa).

Também foi verificada uma influência negativa entre a receita tributária e a reeleição, significando que os eleitores aplicam sanções aos gestores que mais arrecadarem impostos (Cavalcante, 2016; Silva \& Braga, 2013). Ademais, apesar de outros níveis de governo influenciarem na arrecadação de impostos, o esforço para sua coleta é a nível local, sendo que um esforço de coleta fraco (o que frequentemente ocorre) faz com que a carga tributária não seja distribuída igualmente entre todos, levando ao descontentamento dos cidadãos (Brender, 2003).

As transferências intergovernamentais foram retratadas pelos trabalhos de Sakurai e Menezes-Filho (2007, 2008), em que os autores afirmam que as receitas de transferência controlam a relação das receitas totais sobre a probabilidade de reeleição de forma positiva, tendo em vista que gastos mais altos necessariamente precisarão de mais receitas. Além disso, Balaguer-Cool e Brun-Martos (2013) afirmam que quanto maiores os ingressos de transferências recebidas pelos municípios maiores serão as probabilidades do governo local se manter no poder. Assim, como discutido, têm-se como hipóteses desta pesquisa:
$\mathbf{H}_{1}$ : Os aspectos orçamentários exercem influência sobre a reeleição dos prefeitos ou na recondução de partidos nos municípios com mais de 100 mil habitantes no Brasil. $\mathbf{H}_{1 \mathrm{a}}$ : Elevadas despesas com pessoal exercem influência negativa sobre a reeleição e/ou recondução.

$\mathbf{H}_{16}$ : Elevadas despesas de capital exercem influência positiva sobre a reeleição e/ou recondução.

$\mathbf{H}_{1 c}$ : Elevadas arrecadações das receitas próprias exercem influência negativa sobre a reeleição e/ou recondução.

$\mathbf{H}_{\mathrm{ld}}$ : Elevada participação das receitas de transferências exerce influência positiva sobre a reeleição e/ou recondução.

Há de se mencionar que as parcelas não discricionárias dos recursos estão explicadas pela Teoria da Escolha Pública, em que o gestor é menos suscetível de manipulação oportunista, por atender mais atores (e fatores limitadores) envolvidos no processo político (Pereira, 1997; Santos et al., 2021). Enquanto o montante discricionário é mais suscetível ao oportunismo, com indícios dos conflitos de agência e assimetria informacional (Mulgan, 2003).

\subsubsection{Aspectos políticos}

Em relação aos aspectos políticos, destacam-se as análises acerca da ideologia política, percentagem de votos válidos e alinhamento partidário. Sobre a ideologia política, verificou-se que governantes pertencentes a partidos de direita possuem mais sucesso em suas tentativas de reeleição, provavelmente por seu comportamento de cunho mais conservador, com decisões mais tradicionais (Balaguer-Coll et al., 2014; BalaguerColl \& Brun-Martos, 2013). Além disso, no tocante aos votos válidos, Mendes e Rocha (2004a, 2004b) verificaram uma correlação positiva entre o percentual de votos válidos obtidos pelos gestores municipais na primeira eleição e sua probabilidade de reeleição para o segundo mandato. Esse conceito está relacionado à ótica do processo político e da própria eleição como intervenientes da escolha pública. Segundo Brambor e Ceneviva (2012), no processo político existem lacunas para a criação de influências e lobbies que são capazes de influenciar os gestores dos governos em suas escolhas, fazendo-os pender às escolhas públicas dos interessados que os apoia, ou seja, os seus eleitores.

Já com relação ao alinhamento partidário, foram encontradas duas análises específicas: a primeira, com relação ao alinhamento do partido do prefeito ao partido do presidente, enquanto a segunda se relaciona com o alinhamento do partido do prefeito com o do governador do seu estado, sendo que a primeira apresenta uma 
influência negativa ou nula, enquanto a segunda foi positiva (Cavalcante, 2016; Sakurai \& Menezes-Filho, 2008; Sakurai \& Menezes-Filho, 2007; Silva \& Braga, 2013). Cavalcante (2016) afirma, quanto a isso, que parece existir uma dinâmica própria nas relações entre a política estadual e municipal, enquanto parece não ser relevante o alinhamento com $\circ$ governo federal. Assim, têm-se como hipóteses deste estudo:

$\mathbf{H}_{2}$ : Os aspectos políticos exercem influência sobre a reeleição dos prefeitos ou na recondução de partidos nos municípios com mais de 100 mil habitantes no Brasil.

$\mathrm{H}_{2 \mathrm{a}}$ : $\mathrm{O}$ percentual de votos válidos obtidos pelo atual prefeito na eleição anterior exerce influência positiva sobre a reeleição e/ou recondução.

$\mathbf{H}_{2 b}$ : $O$ alinhamento partidário com o governador do estado exerce influência positiva sobre a reeleição e/ou recondução.

$\mathrm{H}_{2 \mathrm{c}}: \mathrm{O}$ alinhamento partidário com $\circ$ presidente da República exerce influência negativa sobre a reeleição e/ ou recondução.

\subsubsection{Aspectos socioeconômicos}

No âmbito dos aspectos socioeconômicos, os estudos identificados avaliam principalmente a influência da densidade demográfica, da renda e desigualdade, bem como do desenvolvimento humano nas chances de reeleição dos governantes. A estrutura macroeconômica afeta diretamente o bem-estar dos indivíduos, que podem avaliar se as condições econômicas se deterioraram ou não para decidir acerca do voto (Aidt et al., 2011; Nordhaus, 1975), bem se essas condições econômicas discricionárias foram ou não manipuladas pelos gestores, evitando-se flutuações (Alesina, 1987).

Em relação à densidade demográfica, Shikida et al. (2009) e Balaguer-Coll e Brun-Martos (2013) verificaram uma influência positiva em relação às chances de reeleição. Já em relação à renda, Shikida et al. (2009) encontraram uma relação positiva entre o Índice de Gini (um indicador de desigualdade que varia de 0 a 1) e a probabilidade de reeleição do gestor. Os autores também encontraram uma relação positiva entre o número de famílias beneficiadas pelo Bolsa Família e as chances de reeleição, apesar de ter se mostrado um resultado de baixa afetação.

O programa Bolsa Família é uma importante política pública criada em 2003 e que realiza transferência direta de renda às famílias em situação de pobreza e extrema pobreza, garantindo o direito à alimentação e maior acesso à saúde e educação, abrangendo toda a população que se encontra em situação de vulnerabilidade social (Ministério da Cidadania, 2020). Sua atuação é baseada em três pilares: maior acesso aos direitos, complementação da renda e estímulo ao desenvolvimento das famílias. Assim, seu principal objetivo é o combate à pobreza e à desigualdade, sendo sua gestão compartilhada entre a União, os estados e os municípios (Ministério da Cidadania, 2020).

Por outro lado, melhores condições socioeconômicas, mensuradas pelo Índice de Desenvolvimento Humano Municipal (IDHM) e pelo Produto Interno Bruto, mostraram uma influência negativa em relação à reeleição (Dias et al., 2018; Meneguin et al., 2005; Silva \& Braga, 2013). Assim, as chances de reeleição parecem ser menores em municípios que já possuem bons indicadores socioeconômicos, o que pode ser reflexo de uma competição eleitoral mais acirrada nesses locais (Meneguin et al., 2005) ou de uma menor necessidade de investir em serviços com o intuito de beneficiar a condição de vida da população. Dessa forma, tem-se como hipóteses:

$\mathbf{H}_{3}$ : Os aspectos socioeconômicos exercem influência sobre a reeleição dos prefeitos ou na recondução de partidos nos municípios com mais de 100 mil habitantes no Brasil.

$\mathbf{H}_{3 a}$ : Os valores do Bolsa Família recebidos pelos municípios influenciam positivamente sobre a reeleição e/ ou recondução.

$\mathbf{H}_{3 b}$ : O PIB per capita influencia negativamente sobre a reeleição e/ou recondução.

\section{Procedimentos Metodológicos}

\subsection{Caracterização da Amostra e Fonte de Dados}

Para o atendimento do objetivo proposto pela pesquisa, a amostra consistiu nos municípios com população superior a 100 mil habitantes de todo o país, de uma população de 5.568 unidades municipais. Os dados contemplaram os exercícios de 2004 a 2016, permitindo analisar a reeleição (ou novos eleitos) dos gestores em quatro eleições municipais: de 2004, 2008, 2012 e 2016, sendo estas determinadas pela disponibilidade de informações durante a realização deste estudo. $O$ número de municípios analisados em cada ano eleitoral correspondeu a 252 no período entre 20042007, 265 entre 2008-2011, 287 entre $2012-2015$ e 308 em 2016 (painel desbalanceado). Assim, foram analisadas um total de 3.524 observações.

As informações contábeis, políticas, e socioeconômicas 
foram de ordem secundária, extraídas das seguintes fontes oficiais: Atlas do Desenvolvimento Humano no Brasil (Atlas Brasil), Finanças Públicas do Brasil (Finbra) disponibilizadas no sítio da Secretaria do Tesouro Nacional (STN), Instituto Brasileiro de Geografia e Estatística (IBGE), Ministério da Cidadania (MC) e Tribunal Superior Eleitoral (TSE). Os valores monetários das variáveis foram ajustados pelo Índice Geral de Preços (IGP-DI), da Fundação Getúlio Vargas (FGV), ao valor corrente do último ano compreendido pela análise. Em relação aos valores monetários, optou-se pelo cálculo do logaritmo dos valores per capita, tendo em vista os valores altos apresentados por elas. Com relação aos outliers, optou-se pela não exclusão dos mesmos, tendo em vista que haveria uma perda significativa do número de observações. A variação dos dados não comprometeu os resultados encontrados nas regressões.

\subsection{Métodos e Variáveis}

Para atingir o objetivo de verificar a influência dos condicionantes socioeconômicos, políticos e orçamentários sobre a reeleição dos gestores municipais (ou a recondução do partido), foi utilizado o procedimento de Regressão Logística Binomial em painel, que permite prever e explicar - comportamento de uma variável dependente do tipo categórica a partir de uma série de variáveis métricas (Hair Jr et al., 2009). As variáveis utilizadas foram descritas no Quadro 1, bem como sua relação esperada, base conceitual e fonte.

Quadro 1: Variáveis, expectativas teóricas e fontes

\begin{tabular}{|c|c|c|c|c|}
\hline \multicolumn{5}{|c|}{ Variável Dependente } \\
\hline $\begin{array}{l}\text { Variável } \\
\text { Dependente }\end{array}$ & \multicolumn{3}{|c|}{ Descrição da Variável } & Fonte \\
\hline ReelPrefeito & \multicolumn{3}{|c|}{$\begin{array}{l}\text { Variável dummy, que indica se o prefeito foi reeleito } \\
\text { ou se houve recondução do partido ao cargo. } \\
\text { Será atribuído valor } 1 \text { para o caso de reeleiçăo ou } \\
\text { recondução, e } 0 \text { caso contrário. }\end{array}$} & TSE \\
\hline \multicolumn{5}{|c|}{ Variáveis Explicativas } \\
\hline $\begin{array}{c}\text { Variável } \\
\text { Explicativa }\end{array}$ & $\begin{array}{l}\text { Descrição das } \\
\text { Variáveis }\end{array}$ & $\begin{array}{l}\text { Relação } \\
\text { Esperada }\end{array}$ & Base Conceitual & Fonte \\
\hline Votval & $\begin{array}{l}\text { Percentual de votos } \\
\text { válidos obtidos pelo } \\
\text { atual prefeito na eleição } \\
\text { anterior. }\end{array}$ & Positiva & $\begin{array}{l}\text { Mendes e Rocha } \\
\text { (2004a, 2004b) }\end{array}$ & TSE \\
\hline LogDespPessoal & $\begin{array}{l}\text { Log das despesas com } \\
\text { pessoal e encargos } \\
\text { sociais per capita }\end{array}$ & Negativa & $\begin{array}{l}\text { Meneguin et al. } \\
(2005)\end{array}$ & FINBRA \\
\hline logDespCap & $\begin{array}{l}\text { Log do somatório das } \\
\text { despesas de capital } \\
\text { liquidadas per capita }\end{array}$ & Positiva & $\begin{array}{l}\text { Meneguin et al. } \\
\text { (2005), Balaguer-Coll } \\
\text { e Brun-Martos (2013), } \\
\text { Balaguer-Coll et al. } \\
\text { (2014), Cavalcante } \\
\text { (2016) }\end{array}$ & FINBRA \\
\hline LogRecPropria & $\begin{array}{l}\text { Log do somatório das } \\
\text { receitas de competênncia } \\
\text { local arrecadadas per } \\
\text { capita }\end{array}$ & Negativa & $\begin{array}{l}\text { Brender (2003), Silva } \\
\text { e Braga }(2013), \\
\text { Cavalcante }(2016)\end{array}$ & FINBRA \\
\hline LogRectransf & $\begin{array}{l}\text { Log do somatório } \\
\text { das receitas de } \\
\text { transferências } \\
\text { intergovernamentais } \\
\text { arreccadadas per capita }\end{array}$ & Positiva & $\begin{array}{l}\text { Sakurai e Menezes- } \\
\text { Fiho (2008) e } \\
\text { Balaguer-Coole Brun- } \\
\text { Marros }(2013)\end{array}$ & FINBRA \\
\hline
\end{tabular}

Fonte: Elaborado pelos autores.

As escolhas de cada dimensão como determinante, contempladas como relacionadas ao pressuposto da assimetria informacional da Teoria de Agência, bem como às Teorias da Escolha Pública e Teoria da Justiça, podem ser explicadas pelas seguintes lógicas e conforme as métricas escolhidas:

- Aspectos orçamentários: a literatura evidencia que as receitas e despesas podem influenciar na probabilidade de reeleição, indicando que tais elementos seriam analisados por parte dos eleitores, influenciando na probabilidade de punição ou premiação do gestor. A realização de maiores despesas de capital aumentaria a probabilidade de reeleição, sendo resultante de sua visibilidade perante os eleitores (Balaguer-Coll et al., 2014). Já o aumento nas despesas correntes, por significarem o custeio da máquina pública, diminuem as probabilidades de reeleição, indicando uma punição por parte dos eleitores (Balaguer-Coll et al., 2014; Brender, 2003). No tocante às receitas, não há consenso sobre a influência das receitas próprias, mas alguns autores evidenciam que os eleitores não aprovariam uma maior arrecadação de impostos, acarretando em uma menor probabilidade de reeleição (Cavalcante, 2016; Silva \& Braga, 2013). De modo contrário, as receitas com transferências de recursos influenciariam positivamente na reeleição indicando uma possibilidade de realização de dispêndios sem que haja uma contrapartida direta por parte dos eleitores (Balaguer-Coll \& Brun-Martos, 2013). Teorias aplicáveis: Agência e Escolha Pública.

- Aspectos políticos: diversas questões de cunho político também podem influenciar na probabilidade de reeleição dos gestores públicos, evidenciando que o eleitor estaria atento à dinâmica política vigente. Nestes termos, o alinhamento partidário com $\circ$ governador implicaria em uma influência positiva, enquanto $\circ$ alinhamento com $\circ$ Presidente da República influenciaria negativamente na reeleição, indicando uma dinâmica própria nas relações entre os três entes (Cavalcante, 2016). É válido destacar 
a questão dos votos válidos obtidos na eleição anterior, que significaria um "estoque" de votos, implicando que haja uma influência positiva na probabilidade de reeleição do gestor nos certames subsequentes (Mendes; Rocha, 2004a, 2004b). Teorias consideradas: Agência e Escolha Pública.

- Aspectos socioeconômicos: A conjuntura municipal também exerce influência sobre a reeleição dos gestores, uma vez que possibilita uma avaliação direta da ação do gestor por parte do eleitor, avaliando os aspectos que trouxeram avanços em sua qualidade de vida. Localidades com melhores indicadores socioeconômicos, onde a necessidade de investimento em programas sociais seria menor, reduzem as possibilidades de reeleição do gestor (Meneguin et al., 2005). Neste sentido, o dispêndio com ○ Bolsa Família afetaria positivamente a probabilidade de reeleição, enquanto melhores condições socioeconômicas influenciariam negativamente na reeleição (Meneguin et al., 2005; Shikida et al., 2009). Teorias aplicadas: Agência e da Justiça.

Diante do exposto, a modelagem desta pesquisa foi:

$$
P(Y=1)=1 / 1+e^{-g(x)}(1)
$$

$g(x)=\beta_{0}+\beta_{1} V_{\text {otVal }}+\beta_{2}$ DespCapital ${ }_{i t}+\beta_{3}$ DespPessoal ${ }_{i t}+\beta_{4}$ RecPropria $_{i t}+\beta_{5}$ RecTransf $_{\text {it }}+\beta_{6}$ AlinGov $_{\text {it }}+\beta_{7}$ AlinPres $_{\text {it }}+\beta_{8}$

$$
\mathrm{BF}_{\text {if }}+\beta_{9} \mathrm{PIBpc}_{\text {if }}+\varepsilon_{\text {it }}
$$

Sendo que:

$P(Y=1)$ : é a probabilidade de a variável dependente ter valor 1, ou seja, de ocorrer o fenômeno de reeleição e/ou recondução;

$\beta_{0}$ : é o intercepto;

i: indica os municípios;

t: anos;

$\varepsilon:$ termo de erro.

Neste estudo, a variável dependente é representada pela reeleição do gestor municipal ou recondução do partido, sendo as demais consideradas como variáveis independentes. A opção pela reeleição e/ou recondução como variável dependente se deu em razão da ocorrência de inúmeros casos em que o gestor não poderia mais ser reeleito por exceder o número de mandatos consecutivos possíveis, mas que seu sucessor eleito era do mesmo partido. Considerou-se, nesses casos, que a opção pela recondução do partido ao cargo se deu em função da satisfação dos cidadãos com o desempenho da gestão, premiando o partido com o voto na impossibilidade de premiação direta do próprio candidato.

Como suplemento ao modelo inicial desta pesquisa, um teste de robustez foi aplicado como potencial de solução à causalidade reversa das variáveis. Para tanto, seguindo os direcionamentos de Lin e Wooldridge (2015); Pickup e Evans (2013), e Lewbel et al. (2012), considerou-se a defasagem (ou lags) das variáveis independentes para períodos anteriores ao ano da eleição, ou seja, de 2005 a 2007 para a eleição de 2008; de 2009 a 2011 para o pleito de 2012, e de 2013 a 2015 para a escolha eleitoral de 2016, para a explicação da sucessão políitico-partidária, dependente, exclusivamente no ano eleitoral (variáveis nos anos de 2008, 2012 e 2016).

\section{Resultados e Discussões}

\subsection{Estatística Descritiva e Correlação}

Consta, na Tabela 1, os valores de média, desvio-padrão, valores mínimo e máximo, assimetria e curtose das variáveis independentes e dependente deste estudo.

Tabela 1: Estatísticas descritivas

\begin{tabular}{|c|c|c|c|c|c|c|}
\hline Variável & Média & $\begin{array}{c}\text { Desvio- } \\
\text {-padrão }\end{array}$ & Mínimo & Máximo & Assimetria & Curtose \\
\hline ReelPrefeito (categórica) & 0,40 & 0,49 & 0 & 1 & 0,36 & 1,13 \\
\hline VotVal (porcentagem) & 0,53 & 0,12 & 0,25 & 1 & 0,77 & 4,17 \\
\hline $\begin{array}{c}\text { DespPessoal (em reais, } \\
\text { per capita) }\end{array}$ & 811,50 & 527,78 & 3,64 & $6.975,58$ & 2,35 & 15,5 \\
\hline $\begin{array}{c}\text { DespCap (em reais, per } \\
\text { capita) }\end{array}$ & 187.47 & 166,24 & 0,28 & $2.492,47$ & 4,25 & 35,65 \\
\hline $\begin{array}{c}\text { RecPropria (em reais, } \\
\text { per capita) }\end{array}$ & 315,01 & 336,51 & 0,51 & $3.776,58$ & 3,36 & 18,12 \\
\hline $\begin{array}{c}\text { RecTransf (em reais, per } \\
\text { capita) }\end{array}$ & $1.165,53$ & 681,40 & 25,63 & $10.406,84$ & 2,53 & 15,59 \\
\hline AlinGov (categórica) & 0,21 & 0,41 & 0 & 1 & 1,39 & 2,93 \\
\hline AlinPres (categórica) & 0,18 & 0,38 & 0 & 1 & 1,64 & 3,71 \\
\hline BF (em reais, per capita) & 52,67 & 52,20 & 0 & 379,26 & 1,92 & 7,56 \\
\hline PIB (em reais, per capita) & $22.762,44$ & $18.645,09$ & $1.706,33$ & $314.637,69$ & 3,52 & 27,95 \\
\hline Fonte: Resultados da pesquisa. & & & & & \\
\hline
\end{tabular}

Em relação a variável dependente, que representa a probabilidade de reeleição do gestor municipal ou recondução do partido ao cargo, verificou-se uma média de 0,40 , com desvio-padrão de 0,49, indicando que cerca de $40 \%$ dos gestores dos municípios em análise foram reeleitos ou houve recondução do partido. Esse valor é condizente com o encontrado por Mendes e Rocha (2004b), que verificaram uma taxa média de reeleição de $40,4 \%$ ao analisar um total de 5.206 municípios brasileiros.

Além disso, verificou-se que em cinco municípios houve a reeleição do gestor ou recondução do partido em todos os ciclos eleitorais analisados, sendo eles: Feira de SantanaBA, Indaiatuba-SP, Praia Grande-SP, Presidente Prudente-SP e Teresina-PI. Com exceção do município de Indaiatuba, os demais sempre reelegeram ou reconduziram o mesmo 
partido nos ciclos eleitorais. Já o município de Indaiatuba, em 2012, reelegeu o prefeito de 2008, mesmo ele estando filiado a um partido diferente. Em 46 municípios, não houve reeleição e nem recondução em nenhum dos ciclos eleitorais analisados.

A percentagem de votos válidos obtidos pelo gestor na eleição anterior apresentou média de 53\%, com valor mínimo de $25 \%$ e máximo de $100 \%$. Este valor máximo foi verificado em três municípios, podendo ser explicado por candidaturas cassadas pelo Tribunal Superior Eleitoral, tendo seus votos anulados ou até mesmo impossibilitado de receber algum voto no pleito. Essa variável representa o patrimônio, ou estoque de votos, que o candidato obteve na eleição anterior, ou seja, permite analisar a fidelidade do eleitor independente da performance do candidato, incorrendo em menores custos de campanha (Mendes; Rocha, 2004b).

As despesas per capita com pessoal e encargos sociais apresentaram uma média de $\mathrm{R} \$ 811,50$, com um desviopadrão de $R \$ 527,78$. O valor mínimo obtido foi de $R \$ 3,64$, referente ao município de Contagem-MG em 2007, enquanto o valor máximo foi de R\$ 6.975,58, relativo a Paulínia-SP em 2016.

Já as despesas de capital per capita, que são relacionadas a investimentos, apresentaram média de $R \$ 187,47$, com um desvio-padrão de $R \$ 166,24$. O valor mínimo obtido foi de $\operatorname{R} \$ 0,28$, referente ao município de Conselheiro Lafaiete-MG em 2016, enquanto o máximo foi $R \$ 2.492,47$, relacionado a Parauapebas-PA, em 2012. Assim, verifica-se que os valores dispendidos em máquinas, imóveis, obras e outros investimentos apresentaram grande variabilidade nos municípios com população acima de 100 mil habitantes.

Em relação às receitas próprias per capita, ou seja, os valores que o município arrecada diretamente por meio de taxas, impostos, dentre outros, verificou-se uma média de $R \$ 315,01$ com um desvio-padrão de $\mathrm{R} \$ 336,51$. O valor mínimo obtido foi de $R \$ 0,51$, referente a Marília-SP, enquanto o valor máximo foi de $R \$ 3.776,58$, associado ao município de Barueri-SP em 2016. Analisando-se os dez maiores valores para a referida variável, seis deles são referentes a Barueri-SP, que possui altos valores de arrecadação do Imposto sobre Serviços de Qualquer Natureza (ISSQN), o que demonstra a grande representatividade do setor de serviços na cidade. Quatro dos dez maiores valores são referentes a Macaé-R, que se destaca pela sua representatividade na exploração do petróleo.

Como medida para equilibrar as finanças, municípios com baixa arrecadação dependem em grande parte das transferências intergovernamentais, o que explica a média alta encontrada para a variável receitas de transferências per capita, que foi de $R \$ 1.165,53$, com um desvio-padrão de $R \$$ 681,40 . O valor mínimo obtido para a variável correspondeu a $R \$ 25,63$, referente a Contagem-MG, enquanto o valor máximo foi de R\$10.406,84, correspondente a Paulínia-SP. Em relação a este último, verificou-se que aproximadamente $85 \%$ das transferências correntes são relacionadas à cotaparte do ICMS devido às atividades de refinaria de petróleo.

Em relação ao alinhamento partidário, verificou-se que, em média, $21 \%$ dos gestores municipais do período em análise eram do mesmo partido do governador e $18 \%$ eram do mesmo partido do presidente da república. Pressupõe-se que a existência de um alinhamento partidário entre os gestores municipais com o estadual e nacional permite mais chances de permanência no poder, além de uma maior facilidade para captar recursos, sendo um fator que pode influenciar a condução das políticas públicas (Cavalcante, 2016; Sakurai \& Menezes-Filho, 2007).

A variável do Programa Bolsa Família representa o nível de vulnerabilidade social do município, tendo em vista que municípios com predominância de famílias carentes terão valores mais altos para a variável. Percebeu-se que a média per capita encontrada foi de $\mathrm{R} \$ 52,67$, com um desvio-padrão de $R \$ 52,20$. O valor máximo de $R \$ 379,26$ foi referente a Abaetetuba-PA, que se destaca pelos altos índices de desemprego, o que pode acarretar um aumento nos valores do Bolsa Família dispendidos. Entretanto, uma investigação da Polícia Federal foi iniciada em 2017 para constatar supostos desvios de dinheiro do referido programa (Polícia Federal, 2017).

Como indicador econômico, foi utilizado o PIB per capita. A média encontrada foi de $\mathrm{R} \$ 22.762,44,62$, com um desvio-padrão de $R \$ 18.645,09$, sendo que $R \$ 1.706,33$ correspondia ao valor mínimo (referente a Cametá-PA) e $\mathrm{R} \$ 314.637,69$ foi o valor máximo encontrado (referente a Paulínia-SP), denotando uma grande variabilidade no fluxo de bens e serviços produzidos pelos entes municipais.

Em relação à correlação entre as variáveis, não tabulada, verificou-se que os maiores coeficientes significativos são entre receitas de transferência e PIB, além de despesas com pessoal e receitas de transferência. Mesmo assim, não há evidência de que as variáveis estejam altamente correlacionadas entre elas, bem como, teoricamente, essas variáveis são necessárias para a modelagem. Para comprovação da não existência de multicolinearidade entre as variáveis, foi realizado o teste VIF, obtendo-se o valor máximo de 8,61, inferior ao limite de 10 recomendado por Hair Jr et al. (2009). 


\subsection{Determinantes da Reeleição lou recondução de partidos) nos municípios brasileiros}

Para se analisar os determinantes orçamentários, políiticos e socioeconômicos na reeleição e/ou recondução foi necessária a definição do modelo de regressão logística binomial com dados em painel mais adequado.

Deste modo, o modelo de efeitos fixos foi comprovado estatisticamente como o mais satisfatório para o estudo. Por sua vez, procedeu-se a aplicação do teste de Wooldridge para se detectar a ausência de autocorrelação entre os resíduos. No entanto, o resultado do teste rejeitou a hipótese nula de não autocorrelação a um nível de confiança de $95 \%$, tornando-se necessárias correções no modelo e optou-se por uma estimação do modelo de efeitos fixos por bootstrap, aumentando a robustez do modelo e corrigindo também a heterocedasticidade (Tabela 2)

Tabela 2: Relação das variáveis determinantes e reeleição, recondução, período de 2004 a 2016

\begin{tabular}{|c|c|c|c|}
\hline Variável & Coeficiente & Erro-padrão & $\mathbf{P}>|\mathbf{z}|$ \\
\hline VołVal & $-0,9980$ & 1,0746 & 0,353 \\
\hline LogDespPessoalPC & $-1,7136$ & $\mathbf{0 , 9 4 5 9}$ & $\mathbf{0 , 0 7 0}{ }^{*}$ \\
\hline LogDespCapPC & $\mathbf{1 , 6 4 9 2}$ & $\mathbf{0 , 2 4 8 5}$ & $\mathbf{0 , 0 0 0}{ }^{* * *}$ \\
\hline LogRecPropriaPC & $-0,6787$ & 0,7687 & 0,377 \\
\hline LogRecTransfPC & 1,3984 & 1,3316 & 0,294 \\
\hline AlinGov & $\mathbf{0 , 3 2 7 1}$ & $\mathbf{0 , 1 7 0 1}$ & $\mathbf{0 , 0 5 5}$ \\
\hline AlinPres & $\mathbf{0 , 7 2 6 0}$ & $\mathbf{0 , 2 1 7 5}$ & $\mathbf{0 , 0 0 1} \mathbf{*}^{* * *}$ \\
\hline BFPC & $\mathbf{0 , 0 0 5 5}$ & $\mathbf{0 , 0 0 2 9}$ & $\mathbf{0 , 0 6 2} \mathbf{*}^{*}$ \\
\hline LogPIBpibPC & $-1,1240$ & 0,7879 & 0,154 \\
\hline Observações & Chow & Hausman & Wooldrigde \\
\hline \multirow{2}{*}{3.012} & 124,26 & 31,70 & $62.217,84$ \\
\cline { 2 - 4 } & 0,0000 & 0,0002 & 0,0000 \\
\hline Log-likelihood & $*$ & $* *$ & $* * *$ \\
\hline -1.400,5415 & $\mathrm{p}<0,10$ & $\mathrm{p}<0,05$ & $\mathrm{p}<0,01$ \\
\hline
\end{tabular}

Fonte: Resultados da pesquisa.

Diante os resultados expostos sobre os aspectos orçamentários, políticos e socioeconômicos evidencia-se que a reeleição e/ ou recondução é influenciada positivamente pelo alinhamento partidário dos prefeitos com os governadores e presidente, pela transferência direta de renda do Programa Bolsa Família e pelas despesas de capital. De modo contrário, as despesas com pessoal mostraram uma relação negativa com a reeleição e/ou recondução.

No tocante aos aspectos políticos, os alinhamentos partidários, com o governo estadual e o federal, demonstraram-se com uma influência positiva com a probabilidade de reeleição e/ou recondução do partido, a significância de tais variáveis corroborou com a literatura. Porém, com relação à expectativa teórica, encontrou-se uma associação divergente. Isso pode ser explicado por a maioria dos trabalhos existentes explorarem um grande número de municípios brasileiros ou estados específicos. Assim, como se optou em analisar os municípios com mais de 100 mil habitantes, restringiu-se o número de unidades de análise, bem como, possibilitou alcançar municípios com maior porte populacional de todos os estados do país e com características distintas entre eles.

Dessa forma, os resultados do alinhamento com o governo federal vão ao encontro às conclusões de Cavalcante (2016), indicando que as relações estabelecidas entre os municípios e os níveis de governo macro interferem na probabilidade de reeleição e/ou recondução do cargo e corroboram os resultados de Sakurai e Menezes-Filho (2007). Isso sugere que, dada a relação cooperativa no sistema federalista entre os três níveis de governo, o alinhamento partidário estreita as relações entre os seus representantes culminando em uma chance maior de captação de recursos e de aplicação dos mesmos, o que pode influenciar nas probabilidades de reeleição ou recondução do partido ao cargo (Sakurai \& Menezes-Filho, 2007). Ademais, o alinhamento também é uma menção da relação oportuna, de informação assimétrica e de benefícios adicionais em comparação aos outros gestores que não são do mesmo agrupamento partidário. Se alinhados, os prefeitos têm mais condições para a atração de recursos via transferências condicionadas, emendas impositivas ou até visitas com caráter populistas que são "bem vistas" pela população (Brambor \& Ceneviva, 2012).

Em relação aos aspectos socioeconômicos, os valores repassados como transferência de renda direta do Programa Bolsa Família, que é uma proxy de vulnerabilidade social do município, demonstraram que aumentos na referida variável levam a acréscimos na probabilidade de reeleição ou recondução do partido ao cargo nos municípios acima de 100 mil habitantes. Este resultado é condizente com os preceitos da Teoria da Justiça, revelando uma preferência por gestores que busquem a equidade e minimização da vulnerabilidade social. Para os eleitores, quando recebedores de transferências de rendas, o sentimento é da igualdade de direitos e da solidariedade coletiva.

Essa constatação ratifica os resultados de Shikida et al. (2009), ao analisarem fatores que interferiram na reeleição do ex-presidente Luís Inácio Lula da Silva. Seus resultados confirmaram o interesse da população por gestores que de alguma forma conseguem trazer mais benefícios aos cidadãos que se encontram em uma situação de vulnerabilidade social. Isso ocorre também nos municípios, de forma que apesar de o programa ser a nível federal, a existência de uma gestão 
compartilhada entre a União, os estados e os municípios permitem que este último seja o protagonista por possuir um contato direto com a população ao realizar os cadastros.

Já em relação aos aspectos orçamentários, as despesas com pessoal apresentaram uma relação negativa, indicando que aumentos de gastos dessa natureza reduzem a probabilidade de reeleição do prefeito ou recondução do partido. Apesar desses valores não serem tão discricionários (por serem obrigações dos governos), estão contemplados nas escolhas públicas dos gestores - de manter a limitação dos gastos com pessoal pela Lei de Responsabilidade Fiscal (legislação) e atender a outros grupos envolvidos no processo políitico, não sendo os servidores públicos como prioritários. Este resultado era aguardado pela expectativa teórica e é igual aos de outros autores, tais como Meneguin et al. (2005), confirmando a relação negativa entre a reeleição e as despesas de pessoal.

Quanto às despesas de capital, verificou-se que sua majoração eleva a probabilidade de reeleição e/ou recondução, corroborando a expectativa teórica adotada. Cavalcante (2016) verificou que dentre vários fatores que influenciavam na probabilidade de reeleição dos prefeitos o mais expressivo era o nível de investimento realizado, culminando em uma probabilidade de $75,5 \%$ a mais de chances. Ainda conforme o autor, quanto maior o esforço dos gestores em investirem na construção de obras e no oferecimento de serviços públicos de interesse social, maiores são suas chances de se reeleger.

Isso implica que o eleitor tende a premiar os governantes que ele julga como os de melhor desempenho, reelegendo-os e incentivando-os a tomarem decisões de interesse público (Cavalcante, 2016). Deveras, Balaguer-Coll et al. (2014) e Balaguer-Coll e Brun-Martos, (2013), verificaram que os eleitores têm preferência pelas despesas de capital em detrimento de despesas correntes, onde se enquadram as despesas com pessoal, o que denota seu maior interesse pelos gastos que podem se reverter no bem-estar do cidadão. Esse comportamento incentiva, inclusive, que os gestores públicos aumentem os gastos com investimentos em períodos próximos às eleições para angariação de maior popularidade perante aos eleitores, dando preferência por obras que impactem direta e imediatamente no bem-estar do cidadão (Dias et al., 2018).

Estas constatações vão ao encontro da discussão realizada por Drazen e Eslava (2010), ao afirmarem que, apesar de não terem conhecimento sobre todas as despesas do governo, os eleitores observam certos tipos de gastos realizados antes da eleição para inferir sobre a qualidade da gestão. No entanto, ainda conforme os autores, quando há uma grande parcela do eleitorado indecisa, o direcionamento dos gastos é mais facilmente compreendido como politicamente motivado, limitando seus efeitos em benefício do gestor. Consta, na Tabela 3, os resultados referentes às hipóteses adotadas no estudo, sinalizando quais foram rejeitadas após a execução da regressão logística com dados em painel. Percebe-se então que os fatores que influenciam na probabilidade de reeleição estão relacionados às despesas, ao alinhamento partidário e ao nível de vulnerabilidade social do município (mensurado pelos recursos dispendidos com o Bolsa Família).

Tabela 3: Situação final das hipóteses adotadas no estudo

\begin{tabular}{|c|c|}
\hline Hipótese & Situação \\
\hline $\begin{array}{l}\mathrm{H}_{1:} \text { : Elevadas despesas com pessoal exercem influência negativa } \\
\text { sobre a reeleição e/ou recondução. }\end{array}$ & Não rejeitada. \\
\hline $\begin{array}{l}\mathbf{H}_{1 \mathrm{~b}} \text { : Elevadas despesas de capital exercem influência positiva } \\
\text { sobre a reeleição e/ou recondução. }\end{array}$ & Não rejeitada. \\
\hline $\begin{array}{l}\mathbf{H}_{\mathrm{h}} \text { : Elevadas arrecadações das receitas próprias exercem } \\
\text { influência negativa sobre a reeleição e/ou recondução. }\end{array}$ & Rejeitada. \\
\hline $\begin{array}{l}\mathbf{H}_{\mathrm{d}} \text { : Elevada participação das receitas de transferências exerce } \\
\text { influência positiva sobre a reeleição e/ou recondução. }\end{array}$ & Rejeitada. \\
\hline $\begin{array}{l}\mathrm{H}_{2 \mathrm{a}} \text { : O percentual de votos válidos obtidos pelo atual prefeito } \\
\text { na eleição anterior exerce influência positiva sobre a reeleição } \\
\text { e/ou recondução. }\end{array}$ & Rejeitada. \\
\hline $\begin{array}{l}\mathbf{H}_{2 b} \text { : } \bigcirc \text { alinhamento partidário com o governador do estado } \\
\text { exerce influência positiva sobre a reeleição e/ou recondução. }\end{array}$ & Não rejeitada. \\
\hline $\begin{array}{l}\mathrm{H}_{2 \mathrm{c}}: \mathrm{O} \text { alinhamento partidário com o presidente da República } \\
\text { exerce influência negativa sobre a reeleição e/ou recondução. }\end{array}$ & Rejeitada*. \\
\hline $\begin{array}{l}\mathrm{H}_{3} \text { : Os valores do Bolsa Família recebidos pelos municípios } \\
\text { influenciam positivamente sobre a reeleição e/ou recondução. }\end{array}$ & Não rejeitada. \\
\hline 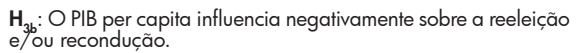 & Rejeitada. \\
\hline
\end{tabular}

* A variável é estatisticamente significativa, mas sua influência é contrária ao esperado. Fonte: Resultados da pesquisa.

Conforme abordado pela Teoria de Agência, podem existir conflitos de interesse entre a figura do agente e dos principais, o que motivaria um comportamento oportunista por parte do agente numa tentativa de maximização de seu bem-estar próprio. Nesta perspectiva, o estudo apontou, num contexto do setor público, dimensões capazes de sofrerem manuseamento pelos agentes com intuito de influenciar na probabilidade de reeleição ou recondução do partido ao cargo. Corroborando com o pressuposto da assimetria informacional da Teoria de Agência e com a possibilidade de existência de um comportamento oportunista por parte dos gestores.

De forma específica, verifica-se que as informações de cunho contábil também podem servir de instrumento de forma vantajosa aos gestores públicos, devido à desigualdade da informação entre agente e principal. Os resultados encontrados ratificam a possibilidade de assimetria, tendo em vista que as variáveis despesa com pessoal e de capital foram significativas e influenciam na reeleição ou recondução. Logo, a divulgação de obras e outros aspectos que indiquem a melhoria da infraestrutura através de despesas de capital são amplamente divulgadas, enquanto as despesas correntes 
que contemplam o custeio da máquina pública possuem pouco destaque no dia a dia dos cidadãos.

Sobre os aspectos orçamentários, pode-se mencionar que apesar do caráter individualista predominante do gestor em suas escolhas, o prefeito, foco desta pesquisa, também é suscetível a toda a pluralidade dos atores, instituições e processos envolvidos nas eleições, que podem direcionar a escolha pública em um caminho mais coletivo e menos discricionários, como discutido na Teoria da Escolha Pública. Nesta teoria permite-se compreender os grupos de interesse e sua influência nas políticas públicas. Segundo Salm (2009), os programas governamentais normalmente oferecem bens públicos "quase amplos", serviços que beneficiam mais a alguns grupos na sociedade que a outros. Neste cenário, os indivíduos interessados em benefícios específicos se organizam para cobrar ações do governo, mas, ao final, os benefícios podem ser compartilhados por todos os contribuintes ou eleitores.

Logo, baseando-se nos resultados obtidos, notou-se que os eleitores tendem a premiar gestores que trazem mais benefícios aos cidadãos de uma forma geral, ou seja, aqueles que tenham como objetivo a promoção do bem-estar coletivo. Isso é verificado na medida em que as despesas com pessoal têm um efeito negativo, enquanto as de capital, o alinhamento com outras esferas de governo e o investimento na redução da vulnerabilidade social (como as transferências de renda e as suas distribuições como preceitos de justiça e reconhecimento de igualdade coletiva), possuem um efeito positivo na probabilidade de reeleição. É relevante destacar que, em um cenário de impossibilidade de reeleição do gestor, os eleitores tendem a premiar os próprios partidos dos governantes, em uma tentativa de continuação dos benefícios adquiridos.

Segundo Pickup e Evans (2013), estudos que utilizam variáveis políticas, econômicas, sociais, financeiras (orçamentárias) estão sujeitos às críticas referentes a endogeneidade nas modelagens. Nesta pesquisa a endogeneidade poderia estar atrelada principalmente à causalidade reversa entre as variáveis dependente e independentes. Wlezien et al. (1997) explicam que essa causalidade é decorrente de que as variações nas escolhas políticas têm influências sobre as variações das percepções sobre a economia ao longo do tempo (e vice-versa), ou seja, as mudanças nas percepções sobre a economia também podem ser estruturadas ou direcionadas pelas mudanças nas escolhas políticas.

Diante desse cenário, aplicou-se como potencial solução para a possível endogeneidade existente na modelagem as recomendações de lin e Wooldridge (2015); Pickup e
Evans (2013), e Lewbel et al. (2012), de a consideração no modelo de retrospectivas (ou defasadas temporalmente ou lags das variáveis) das condições econômicas, sociais, financeiras (orçamentárias) para explicação da variável dependente política a acontecer. Considerou-se que as variáveis econômicas, sociais, financeiras (orçamentárias) já aconteceram antes da escolha política de reeleição ou recondução de gestores subnacionais - amenizando-se a possibilidade da causalidade reversa, pois a captura é de eventos já ocorridos nas variáveis independentes para influenciar algo a ocorrer na variável dependente.

Assim, considerando-se os ciclos eleitorais desta pesquisa, os testes robustos foram da seguinte maneira:

- Reeleição ou recondução do partido (dependente): variáveis consideradas somente para os anos eleitorais: 2008, 2012 e 2016;

- Variáveis Independentes (econômicas, políticas, orçamentárias): foram utilizadas as médias das variáveis para os três anos anteriores ao eleitoral para prever o resultado da eleição. Logo: para o ano eleitoral de 2008, as variáveis independentes foram consideradas pelas médias dos anos de 2007, 2006 e 2005; para 2012, as médias foram para os períodos de 2011, 2010 e 2009, e para 2016, os anos considerados foram de 2015, 2014 e 2013.

A utilização da média e das defasagens foram para eliminar - "efeito calendário", em que prefeitos tendem a ser mais austeros em anos não eleitorais e gastar mais em anos eleitorais (Pickup \& Evans, 2013). Nesse sentido, os resultados encontrados estão na Tabela 4.

Tabela 4: Modelo de Robustez, na relação das variáveis determinantes e reeleição, recondução, período de 2004 a 2016

\begin{tabular}{|c|c|c|c|}
\hline Variável & Coeficiente & Erro-padrão & $P>|z|$ \\
\hline VotVal & $-1,4368$ & 0,7995 & $0,072 *$ \\
\hline LogDespPessoalPC & $-2,8539$ & 1,5044 & $0,058^{*}$ \\
\hline LogDespCapPC & 1,7290 & 0,3166 & $0,000 * * *$ \\
\hline LogRecPropriaPC & $-0,2181$ & 0,9269 & 0,814 \\
\hline LogRecTransfPC & 2,3006 & 1,9039 & 0,227 \\
\hline AlinGov & 0,3713 & 0,1747 & $0,034 * *$ \\
\hline AlinPres & 0,6909 & 0,2280 & $0,002^{* * *}$ \\
\hline BFPC & 0,0031 & 0,0030 & 0,300 \\
\hline LogPIBpibPC & $-1,0289$ & 0,9188 & 0,263 \\
\hline Observações & Chow & Hausman & Wooldrigde \\
\hline \multirow{2}{*}{1.431} & 82,76 & 34,95 & 5,28 \\
\hline & 0,0000 & 0,0001 & 0,0000 \\
\hline Log-likelihood & $*$ & $* *$ & $* * *$ \\
\hline$-572,1077$ & $p<0,10$ & $p<0,05$ & $p<0,01$ \\
\hline
\end{tabular}


Fonte: Resultados da pesquisa. Observações: Para a validação, sob a ótica dos efeitos, do modelo em painel de regressão logística, foram aplicados os testes de Chow e Hausman, sendo o modelo de efeitos fixos o mais adequado. Além disso, foi realizado também o teste de Wooldridge para verificar a presença de autocorrelação, os resultados rejeitaram a hipótese nula de ausência de autocorrelação, tornando-se necessárias correções no modelo e optou-se por uma estimação do modelo de efeitos fixos por bootstrap. Tanto o modelo inicial, Tabela 2, quanto o modelo de robustez foram estimados de modo igual com base nos testes realizados, os dois modelos são de efeitos fixos por bootstrap. No caso das variáveis dummy de alinhamento político-partidário com o governador e com o presidente, utilizou-se o valor 1 se em ao menos um dos três anos anteriores ao ano eleitoral houve alinhamento, e utilizou-se 0 se não houve alinhamento em ano algum.

Com a aplicação das defasagens ou lags instrumentais das variáveis independentes, os resultados encontrados são consideravelmente similares para o modelo inicial da pesquisa, de achados na Tabela 2 com os da Tabela 4. As variáveis independentes, LogDespPessoalPC, LogDespCapPC, AlinGov e AlinPres, mantiveram as significâncias e os sinais encontrados (as não significantes permaneceram como quase todas as mesmas). Somente houve uma modificação, a variável VołVal - a explicação para o sinal encontrado é que os gestores não desfrutam da vantagem eleitoral na eleição anterior, pois ocorre desgaste de sua imagem, mais preparo da oposição e ações contrárias contra a perpetuação política no poder (Brambor \& Ceneviva, 2012) - se tornou significativa em detrimento da variável BFPC. Porém, essa modificação não invalida os achados e se demonstra que o potencial de correção da endogeneidade é favorável à confirmação das discussões realizadas nas hipóteses deste estudo.

\section{Considerações finais}

O estudo possuía como expectativa três hipóteses gerais: os aspectos orçamentários $\left(\mathrm{H}_{1}\right)$, políticos $\left(\mathrm{H}_{2}\right)$ e socioeconômicos $\left(\mathrm{H}_{3}\right)$ exercem influência sobre a reeleição dos prefeitos ou na recondução de partidos nos municípios com mais de 100 mil habitantes no Brasil. Com base nos resultados obtidos, não se rejeitou nenhuma das hipóteses, comprovando que as três dimensões possuem relação com a probabilidade de reeleição e/ou recondução. De modo específico, algumas sub hipóteses sobre os aspetos orçamentários, políticos e socioeconômicos foram rejeitadas, sendo elas: as receitas próprias $\left(H_{1 c}\right)$, as receitas de transferências $\left(H_{1 d}\right)$, o percentual de votos válidos $\left(\mathrm{H}_{2 \mathrm{a}}\right)$ e o PIB $\left(\mathrm{H}_{3 \mathrm{~b}}\right)$. A rejeição destas infere que nenhuma delas possui relação com a probabilidade de reeleição e/ou recondução.

Os resultados deste estudo indicaram que os eleitores tendem a premiar os gestores que se mostram mais preocupados com - bem-comum e a busca pelo bem-estar social, elegendo aqueles que se mostram mais empenhados em realizar obras e outros investimentos no município, em uma tentativa de garantir maior qualidade de vida aos residentes. De modo contrário, gestores que tendem a realizar muitos dispêndios com folla de pagamento, o que poderia tornar a gestão pública um mero ente empregador, são penalizados pelos eleitores, passando a ter uma menor probabilidade de reeleição e prejudicando também as probabilidades de recondução do próprio partido ao cargo.

De modo adicional, para as despesas de capital, recursos mais discricionários de dispêndios, situa-se que seus incentivos para a reeleição estão na política adotada pelo gestor, em agradar aos seus eleitores, bem como seus potenciais, com ações visíveis - como a construção de prédios, edifícios ou praças - que levam a uma troca voluntária e benéfica que gera o bem-estar das partes envolvidas.

É interessante ressaltar que os resultados indicam a preocupação dos eleitores com as ações dos gestores municipais, revelando que os mesmos tendem a penalizar condutas que são expressadas pelos aspectos orçamentários, políticos e socioeconômicos, como comportamentos que possam priorizar interesses próprios dos gestores públicos. Assim, justifica-se a premiação aos gestores ou partidos com a reeleição ou recondução daqueles que priorizam as necessidades dos cidadãos. Tendo em vista a utilização de uma análise de dados em painel, considerando os quatro ciclos eleitorais, percebe-se que essa análise da conduta dos gestores parece ser algo perene no tempo, não tendo sido constatada em apenas uma eleição.

Permitiu-se concluir, por meio dos pressupostos da assimetria informacional (Teoria de Agência), do comportamento oportunista visando bem-estar próprio coletivo e relacional (Teoria da Escolha Pública), bem como da busca pela justiça social (Teoria da Justiça), dimensões que podem ser exploradas pelo agente no setor público. A utilização destas em seu favorecimento demonstra que possa haver um comportamento oportunista, e a reeleição ou recondução em benefício próprio que estes visam alcançar. Evidenciaramse principalmente essa possiblidade de comportamento com o estabelecimento de alinhamentos político-partidários, influência em uma gestão compartilhada do Programa Bolsa Família e uma ampla divulgação dos gastos de capital.

Tal constatação vai de encontro com a questão de angariação de popularidade junto aos eleitores, ou seja, a chance de construção da imagem de um agente que visa alcançar os objetivos estipulados pela sociedade, e não objetivos próprios. Destaca-se também o resultado obtido para os dispêndios com o Programa Bolsa Família, que se relacionaram positivamente na probabilidade de reeleição 
ou recondução. Isso indica que o município poderia ter um aproveitamento do papel de cadastrador dos cidadãos em um programa que é de cunho federal, beneficiando-se sem que tenha reais dispêndios financeiros, visto que o governo federal é o responsável pelas transferências de renda.

A contribuição teórica deste estudo está em que a reeleição é sujeita às influências e à utilização do orçamento, das relações políticas e fatores sociais na governança pública, de utilizar esses elementos para manter ou atrair novos eleitores, políticos partidários e outros grupos, mantendo-se uma relação de troca voluntária entre o candidato e esses interessados. Ademais, um ponto de discussão vem da ótica de responsabilização e transparência, de mecanismos a serem aplicados para evitar a utilização da eleição ou dos anos de mandatos para manipular o eleitor, com a utilização de informações modificações ou em situações de suavizações (ou seja, evitar a flutuação normal dos resultados obtidos no município).

Em aspectos práticos, neste estudo demonstra-se a importância para que eleitores tornem a transparência ativa e com sua participação social. Informações demandadas são aquelas utilizáveis e todas aqui consideradas (orçamentárias, políticas e socioeconômicas) e significativas no modelo são públicas e acessíveis, permitindo-se a coleta dos eleitores para as suas escolhas eleitores. Além disso, houve no trabalho indícios, de situações retratadas recorrentemente na mídia, de a questão oportunista de como os administradores públicos podem se utilizar do aparato estatal para promover a sua reeleição ou a de seu sucessor.

Como limitação deste estudo, consta a dificuldade na obtenção de mais variáveis que estivessem disponíveis durante todo o período analisado, o que impediu conclusões acerca de mais elementos e mais ciclos eleitorais e sua influência na probabilidade de reeleição e/ou recondução. Aditivamente, sugerem-se estudos com variáveis coletadas primariamente dos eleitores para percepções não captadas em dados "prontos". A comparação internacional também é uma pesquisa desejável para esta área.

Apesar da existência de legalidade das reeleições e reconduções, o estudo demonstrou que existem formas de os gestores públicos influenciarem através de suas atribuições para que os mesmos aconteçam. Deste modo, sugere-se, para estudos futuros, a investigação acerca da possibilidade de reeleição e de recondução serem satisfatórias para os cidadãos ou se apenas ocorre o que foi evidenciado neste estudo: uma possível utilização da assimetria informacional para alcançar benefícios próprios ao invés de, de fato, os agentes agirem conforme os interesses do principal. Sugere- se a ampliação desta análise para todos os municípios brasileiros, potencializando consideravelmente a capacidade preditiva das análises.

\section{Referências}

Aidt, T. S., Veiga, F. J., \& Veiga, L. G. (2011). Election results and opportunistic policies: A new test of the rational political business cycle model. Public choice, 148(1), 21 44. 10.1007/s 111 127-010-9644-3

Alesina, A. (1987). Macroeconomic Policy in a TwoParty System as a Repeated Game. The Quarterly Journal of Economics, 102(3), 651-678. https://doi. org/10.2307/1884222

Alesina, A. (1988). Credibility and policy convergence in a two-Party system with rational voters. American Economic Review, 78, 796-806.

Alesina, A., \& Roubini, N. (1992). Political cycles in OECD economies. The Review of Economic Studies, 59(4), 663-688. 0034-6527/92/00350663\$02.00

Akhmedov, A., \& Zhuravskaya, E. (2004). Opportunistic political cycles: test in a young democracy setting. The quarterly journal of economics, 119(4), 1301-1338.

Balaguer-Coll, M. T., \& Brun-Martos, M. I. (2013). El efecto del gasto público sobre las posibilidades de reelección de los gobiernos locales. Revista de Contabilidad, 16(1), 7480. https://doi.org/10.1016/S1138-4891(13)70008-6

Balaguer-Coll, M. T., Brun-Martos, M. I., Forte, A., \& TortosaAusina, E. (2014). Determinants of local governments' reelection: New evidence based on a Bayesian approach. Economics Department, Universitat Jaume I, 1-31.

Barreto, A. A. de B. (2009). Reeleição para o executivo municipal no Brasil (2000-2008). Revista Debates, 3(2), 97-1 15.

Bovens, M., Schillemans, T., \& Hart, P. T. (2008). Does public accountability work? An assessment tool. Public Administration, 86(1), 225-242. https://doi. org/10.1111/j.1467-9299.2008.00716.x

Brambor, T., \& Ceneviva, R. (2012). Reeleição e continuísmo nos municípios brasileiros. Novos Estudos CEBRAP, 93, 9-21. https://doi.org/10.1590/S010133002012000200002

Brasil. (1997). Emenda Constitucional no 16, de 04 de 
junho de 1997. Dá Nova Redação ao § 50 do Art. 14, ao Caput do Art. 28, ao Inciso II Do Art. 29, ao Caput do Art. 77 e Ao Art. 82 da Constituição Federal.Recuperado de http://www.planalto.gov.br/ccivil_03/constituicao/ emendas/emc/emc 16.htm

Brender, A. (2003). The effect of fiscal performance on local government election results in Israel: 1989-1998. Journal of Public Economics, 87(9-10), 2187-2205. https://doi.org/10.1016/S0047-2727(02)00045-2

Brender, A., \& Drazen, A. (2008). How do budget deficits and economic growth affect reelection prospects? Evidence from a large panel of countries. American Economic Review, 98(5), 2203-20.

Calgaro, C. (2016). O programa bolsa família e a teoria da justiça de John Rawls: a emancipação e a autonomia dos beneficiários. Revista Electrónica Direito e SociedadeREDES, 4(2), 91-103.

Cavalcante, P. (2015). Vale a pena ser um bom prefeito? Comportamento eleitoral e reeleição no Brasil. Opiniao Publica, 21(1), 87-104. https://doi.org/10.1590/1807. 019121187

Cavalcante, P. (2016). Desempenho fiscal e eleições no Brasil: uma análise comparada. Revista de Administração Pública, 50(2), 307-330.

Cervi, E. U. (2002). Comportamento eleitoral volátil e reeleição: as vitórias de Jaime Lerner no Paraná. Revista de Sociologia e Política, 19, 123-134. https://doi. org/10.1590/s0104-44782002000200009

Conselho Federal de Contabilidade. (2016). NBC TSP estrutura conceitual. Normas Brasileiras de ContabilidadeTransações Do Setor Público-Estrutura Conceitual Para Elaboração e Divulgação de Informação Contábil de Propósito Geral Pelas Entidades Do Setor Público. Recuperado de https://wwwl.cfc.org.br/sisweb/SRE/ docs/NBCTSPEC.pdf

Chortareas, G., Logothetis, V., \& Papandreou, A. A. (2016). Political budget cycles and reelection prospects in Greece's municipalities. European Journal of Political Economy, 43, 1-13. https://doi.org/10.1016/i. ejpoleco.2016.02.001

Cunha, A. M., Ferreira, A. C. S., \& Fernandes, M. J. (2018). Information and Socioeconomic Factors in the ReElection of Portuguese Mayors. In Handbook of Research on Modernization and Accountability in Public Sector Management, Chapter 19. USA: IGI GLOBAL.

Dias, B. P., Nossa, V., \& Monte-Mor, D. S. (2018). O investimento público influencia na reeleição? Um estudo empírico nos municípios do estado do Espírito Santo. Revista de Administração Pública, 52(5), 880-898.

Drazen, A., \& Eslava, M. (2010). Electoral manipulation via voter-friendly spending: Theory and evidence. Journal of development economics, 92(1), 39-52.

Hair Jr, J. F., Black, W. C., Babin, B. J., Anderson, R. E., \& Tatham, R. L. (2009). Análise Multivariada de dados (6th ed.). Porto Alegre: Bookman.

Islam, F. (2015). New Public Management (NPM): A dominating paradigm in public sectors. African Journal of Political Science and International Relations, 9(4), 141151. https://doi.org/10.5897/ajpsir2015.0775

Jensen, M. C., \& Meckling, W. H. (1976). Theory of the firm: Managerial behavior, agency costs and ownership structure. Journal of Financial Economics, 3, 305-360. https://doi.org/10.1016/0304-405X(76)90026-X

Kalimullah, N. A., Alam, K. M. A., \& Nour, M. M. A. (2012). New Public Management: Emergence and Principles. BUP Journal, 1(1), 1-22.

Lewbel, A., Dong, Y., \& Yang, T. T. (2012). Comparing features of convenient estimators for binary choice models with endogenous regressors. Canadian Journal of Economics, 45(3), 809-829. https://doi.org/10.1111/ j. 1540-5982.2012.01733.x

Liendo, N. A. (2014). Análisis comparado de los factores institucionales que impiden la reelección de los gobernadores argentinos. Civilizar, 14(26), 87-113. https://doi.org/10.22518/16578953.143

Lin, W., \& Wooldridge, J. M. (2015). On different approaches to obtaining partial effects in binary response models with endogenous regressors. Economics Letters, 134, 58-61. 10.1016/i.econlet.2015.05.019

Medeiros, K. R. D., Albuquerque, P. C. D., Tavares, R. A. W., \& Souza, W. V. D. (2017). Lei de Responsabilidade Fiscal e as despesas com pessoal da saúde: uma análise da condição dos municípios brasileiros no período de 2004 a 2009. Ciência \& Saúde Coletiva, 22, 1759-1769. https:// doi.org/10.1590/1413-81232017226.22852016 
Mendes, M., \& Rocha, C. A. A. (2004a). O que Reelege um Prefeito? (pp. 1-55). Senado Federal, Consultoria Legislativa. https://doi.org/10.13140/ RG.2.2.27628.82560

Mendes, M., \& Rocha, C. A. A. (2004b). Reeleição sob Informação Imperfeita: Evidências para os municípios brasileiros. (pp. 1-24). Departamento de Economia, Universidade de Brasília. Texto no 313. Série Textos para discussão. https://doi.org/10.13140/ RG.2.2.32661.99046

Meneguin, F. B., \& Bugarin, M. S. (2001). Reeleição e Política Fiscal: um estudo dos efeitos da reeleição nos gastos públicos. Revista Economia Aplicada, 5(3), 601622.

Meneguin, F. B., Bugarin, M. S., \& Carvalho, A. X. de. (2005). O que leva um governante à reeleição. IPEA (Insituto de Pesquisa Econômica Aplicada). Texto para Discussão no 1135.

Ministério da Cidadania. (2020). Bolsa Família. Recuperado de https://www.gov.br/cidadania/pt-br/ acoes-e-programas/bolsa-familia

Mulgan, R. (2003). Holding Power to Account: Accountability en Modern Democracies. New York: Palgrave Macmillan.

Nordhaus, W. D. (1975). The political business cycle. The review of economic studies, 42(2), 169-190.

Pereira, P. T. (1997). A teoria da escolha pública (public choice): uma abordagem neoliberale Análise Social, 32(141), 419-442. http://www.jstor.org/ stable/41011271

Pereira, C., \& Renno, L. (2007). O que é que o reeleito tem? O retorno: o esboço de uma teoria da reeleição no Brasil. Revista de Economia Política, 27(4), 664-683.

Polícia Federal. (2017). PF investiga desvio de recursos do Bolsa Família. Recuperado de http://www.pf.gov. br/agencia/noticias/2017/05/pf-investiga-desvio-derecursos-do-bolsa-familia

Pickup, M., \& Evans, G. (2013). Addressing the Endogeneity of Economic Evaluations in Models of Political Choice. Public Opinion Quartely, 77(3), 735-754. https:// doi.org/10.1093/poq/nft028
Portella, A. A., \& Teixeira, R. P. (2016). Federalismo fiscal e efetividade da dignidade da pessoa humana: análise da posição do município na estrutura do financiamento público brasileiro e a escassez de recursos para as ações de saúde. Revista de Direito da Cidade, 8(2), 631-679. $10.12957 /$ rdc. 2016.21506

Rawls, J. (1971). A theory of justice. Harvard University press.

Rogoff, K., \& Sibert, A. (1988). Elections and macroeconomic policy cycles. The review of economic studies, 55(1), 1-16. 0034-6527/88/00010001\$02.00

Sakurai, Sergio Naruhiko, \& Menezes-Filho, N. A. (2008). Fiscal policy and reelection in Brazilian municipalities. Public Choice, 137, 301-314. https://doi.org/10.1007/ s 111 27-008-9329-3

Sakurai, Sérgio Naruhiko, \& Menezes-Filho, N. A. (2007). Política fiscal e reeleição nos municípios brasileiros: uma análise via dados em painel para o período 1988-2000. Encontro Nacional de Economia, 35, 1-20.

Sakurai, S. N., \& Menezes-Filho, N. (2011). Opportunistic and partisan election cycles in Brazil: new evidence at the municipal level. Public Choice, 148(1), 233-247.

Salm, José Francisco. (2009). Políticas públicas e desenvolvimento: bases espistemológicas e modelos de análise. Brasília: Ed. Univ. de Brasília.

Santos, D. V., Costa, P. S. \& Azevedo, R. R. (2021). Descentralização da execução da despesa orçamentária e seu efeito no gasto municipal. Advances in Scientific and Applied Accounting, 14(1), 141-159. http://dx.doi. org/10.14392/asaa.2021140105

Shikida, C. D., Monasterio, L. M., Araujo Jr, A. F. de, Carraro, A., \& Damé, O. M. (2009). It is the economy, companheiro!": an empirical analysis of Lula's re-election based on municipal data. Economics Bulletin, 29(2), 1-14.

Shi, M.; Svensson, J. (2006). Political budget cycles: Do they differ across countries and why? Journal of Public Economics, 90(8-9), 1367-1389. https://doi. org/10.1016/i.jpubeco.2005.09.009

Silva, F. D. F., \& Braga, M. J. (2013). Determinantes da reeleição municipal da Bahia para o período de 2000 2008. Planejamento e Políticas Públicas, 40, 257-276.

Veiga, L. F., Santos, S. A. dos, \& Neves, D. S. (2011). 
Como a avaliação do governo local, a imagem dos Wlezien, C., Franklin, M., \& Twiggs, D. (1997). candidatos e a configuração da disputa influenciam na Economic Perceptions and Vote Choice: Disentangling the reeleição do prefeito: Evidências de oito capitais no Brasil. Endogeneity. Political Behavior, 19(1), 7-17. http://www. World Association for Pubilic Opinion Research, 1-30. jistor.org/stable/586547 